\title{
STRUCTURAL DISTORTIONS OF COORDINATED KETENE MOLECULE INDUCED BY THE PSEUDO JAHN-TELLER EFFECT
}

\author{
Natalia Gorinchoy \\ Institute of Chemistry of Academy of Sciences of Moldova, 3, Academiei str., Chisinau MD-2028, Republic of Moldova \\ e-mail:ngorinchoy@yahoo.com
}

\begin{abstract}
It is demonstrated that the only reason of structural distortions of ketene molecule coordinated in the complexes $\mathrm{VCp}_{2}-\mathrm{H}_{2} \mathrm{C}_{2} \mathrm{O}$ (I) and $\mathrm{Pt}\left(\mathrm{PPh}_{3}\right)_{2}-\mathrm{H}_{2} \mathrm{C}_{2} \mathrm{O}$ (II) is the pseudo Jahn-Teller effect (PJTE) induced by the orbital charge transfers (OCTs) by coordination. It is shown that the $\eta^{2}-(\mathrm{C}-\mathrm{O})$ coordination and the in-plane $b_{2}$-type distortion of ketene in the complex (I) is due to the PJTE induced by the back donation to its LUMO $3 b_{2}\left(\pi_{\mathrm{CO}}{ }^{*}\right)$. The $\eta^{2}-(\mathrm{C}-\mathrm{C})$ coordination mode, as well as the out-of-plane $b_{1}$-type distortion of the molecule in the complex (II) is caused by two OSTs: from the HOMO $2 b_{1}\left(\pi_{\mathrm{CC}}\right)$ to the metal, and from the $d_{\mathrm{xy}}$ - atomic orbital (AO) of the atom of Pt to the vacant $3 b_{1}\left(\pi_{\mathrm{CC}}{ }^{*}\right)$ molecular orbital (MO) of ketene, thus being the result of the diorbital Pt-ketene interaction. The necessary parameters of the PJTE were estimated by considering the excited states of free ketene molecule, and the values of the OSTs were obtained from the electronic structure calculations of the complexes.
\end{abstract}

Keywords: Pseudo Jahn-Teller effect, orbital charge transfers, ketene excited states, metal ketene complex.

Received: November 2016/Revised final: December 2016/ Accepted: December 2016

\section{Introduction}

The case of coordinated ketene molecule is interesting in that ketenes can be bound to transition metal complexes in a variety of ways. To date, a number of complexes with ketenes were synthesized and structurally determined by X-ray diffraction [1-7]. It is generally accepted that early transition metal complexes favor the $\eta^{2}-(\mathrm{C}-\mathrm{O})$ bonding mode [3,6], the $\eta^{2}-(\mathrm{C}-\mathrm{C})$ mode is preferred by late transition metal complexes [2,7]. Moreover, in the first case the ketene molecule undergoes the in-plane distortion, while the $\eta^{2}-(\mathrm{C}-\mathrm{C})$ coordination mode leads to the out-of-plane distortion of ketene $[1,7,8]$. Some theoretical investigations of ketene binding to $\mathrm{Ni}, \mathrm{Pt}$ [7], and $\mathrm{Pd}$ [8] were reported. These computational studies show that Ni binds ketene molecule through the $\eta^{2}-(\mathrm{C}-\mathrm{O})$ coordination mode, and $\mathrm{Pd}$ and $\mathrm{Pt}$ prefer the $\eta^{2}-(\mathrm{C}-\mathrm{C})$ binding mode. However, the origin of instability of coordinated ketene high-symmetry $\left(\mathrm{C}_{2 \mathrm{v}}\right)$ nuclear configuration and its distortions in different complexes were not considered.

In the present paper, we apply a new approach to handle instabilities and structural changes in coordinated and adsorbed molecules [9] in order to reveal the origin of structural distortions of ketene molecule coordinated in two transition metal complexes, $\mathrm{VCp}_{2}-\mathrm{H}_{2} \mathrm{C}_{2} \mathrm{O}(\mathrm{I})$ and $\mathrm{Pt}\left(\mathrm{PPh}_{3}\right)_{2}-\mathrm{H}_{2} \mathrm{C}_{2} \mathrm{O}$ (II). It is based on an approximate evaluation of the Jahn-Teller effect (JTE), pseudo JTE (PJTE), and Renner-Teller effect (RTE) induced by the orbital charge transfers (OCTs) in such systems. This theoretical approach proved to be effective and predictable in rationalization of experimental data regarding the distortion of coordinated molecules [9-11]. It was shown that in-plane $b_{2}$-type distortion of ketene molecule, coordinated in the complex (I) is explained as due to the PJTE induced by the back donation to its LUMO $3 b_{2}\left(\pi_{\mathrm{CO}}{ }^{*}\right)$. The $\eta^{2}-(\mathrm{C}-\mathrm{C})$ coordination mode, as well as the out-of-plane $b_{1}$-type distortion of the molecule in the complex (II) is caused by the two OCTs: from the HOMO $2 b_{1}\left(\pi_{\mathrm{CC}}\right)$ to the metal, and from the $d_{\mathrm{xy}}$ - atomic orbital (AO) of Pt to the vacant $3 b_{1}\left(\pi_{\mathrm{CC}}{ }^{*}\right)$ molecular orbital (MO) of ketene.

\section{Theoretical model and computational details}

Coordination of a ligand to the transition metal complex is accompanied by the formation of bonding molecular orbitals (MOs) between the metal and the ligand. Due to formation of these bonding MOs the orbital charge transfers (OCT) to or from coordinated molecule take place. We assume that the influence of these small OCTs $\Delta q(\Delta q<<n e$, where $n$ is the number of electrons in the molecule) can be considered as a small perturbation to the integer-electron system. Then, in the first order of perturbation theory, it can be presumed that the additional charge occupies any vacant $\mathrm{MO}$ of the molecule or leaves one of the occupied MO without changing significantly the MO wavefunctions. These OCTs influence the PJTE in coordinated molecules leading to the instability and distortion of their high-symmetry nuclear configurations.

In the pseudo Jahn-Teller effect the problem of the stability or instability of molecular nuclear configuration with respect to any symmetrized coordinate $Q$ may be reduced to the consideration of the curvature $K$ of the adiabatic potential energy surface (APES) at $Q=Q_{0}$ in the direction of $Q$. In the second order perturbation theory with respect to small nuclear displacements from the reference point $Q_{0}$ the expression for $K$ is given by Eq.(1) [12]:

$K=K_{0}-\sum_{i} 2\left|F_{Q}^{(1, i)}\right|^{2} / \Delta_{i}$ 
where

$$
F_{Q}^{(1, i)}=\left\langle 1\left|(\partial H / \partial Q)_{0}\right| i\right\rangle
$$

is the vibronic coupling constant between the reference $|1\rangle$ and higher in energy excited state $|i\rangle, \Delta_{i}$ is the energy gaps between the mixing states, $K_{0}$ is the primary force constant (the force constant without the PJTE), and $H$ is the Hamiltonian of the electronic subsystem in the adiabatic approximation. In the particular case of two mixing states $|1\rangle$ and $|2\rangle$ the value of $K$ is given by Eq.(3):

$$
K=K_{0}-2\left|F_{Q}^{(1,2)}\right|^{2} / \Delta_{12}
$$

and the distortion of a nondegenerate state $|1\rangle$ in the $Q$ direction takes place when the inequality Eq.(4) holds:

$$
\left(\left|F_{Q}^{(1,2)}\right|^{2} / \Delta_{12}\right)>K_{0}
$$

In the "frozen orbital" approximation it is assumed that the $|1\rangle \rightarrow|2\rangle$ excitation can be described by the one-electron excitation $|i\rangle \rightarrow|j\rangle$ that changes the occupations of molecular orbitals $|i\rangle$ and $|j\rangle$, while the other MOs remain unchanged. In this case the off-diagonal matrix element $F_{Q}^{(1,2)}$ can be simply expressed (Eq.(5)) by means of the off-diagonal orbital vibronic coupling constant (OVCC) $f_{Q}^{(i, j)}[12]$,

$$
F_{Q}^{(1,2)} \approx f_{Q}^{(i, j)}=\left\langle i\left|(\partial H / \partial Q)_{0}\right| j\right\rangle
$$

In [9] it was shown that in this case the curvature $K^{\text {coord }}$ of the APES of coordinated molecule along the distortion coordinate can be expressed by Eq.(6).

$$
K_{Q}^{\text {coord. }}=K_{Q}^{\text {free }}-2 \sum_{i, j}\left(\Delta q_{i}-\Delta q_{j}\right)\left|f_{Q}^{(i, j)}\right|^{2} / \Delta_{i j}
$$

Here $K^{\text {free }}$ is the curvature of the APES of free molecule in the $Q$ direction, $\Delta q_{i}$ and $\Delta q_{j}$ are the OCTs to or from the molecular orbitals $\mid i>$ and $|j\rangle$, and $f_{Q}^{(\mathrm{i}, j)}$ is the off-diagonal OVCC between them. The condition of instability in the $Q$ direction Eq.(4) in this case can be rewritten as

$$
2 \sum_{i, j}\left(\Delta q_{i}-\Delta q_{j}\right)\left|f_{Q}^{(i, j)}\right|^{2} / \Delta_{i j}>K_{Q}^{\text {free }}
$$

If the inequality Eq.(7) holds then $K^{\text {coord }}<0$ which shows that the molecule is unstable with respect to the symmetrized coordinate of nuclear displacements Q. To estimate the value of $K^{\text {coord }}$ we need to calculate the curvature of the APES of free molecule $\left(K^{\text {free }}\right)$ in this direction, to evaluate the PJT coupling constants $f_{Q}^{(i, j)}$ and the orbital charge transfers $\Delta \mathrm{q}_{\mathrm{i}}$ induced by coordination.

To do this, we performed the electronic structure calculations of the free ketene molecule and the complexes $\mathrm{VCp}_{2}-\mathrm{H}_{2} \mathrm{C}_{2} \mathrm{O}(\mathrm{I})$ and $\mathrm{Pt}\left(\mathrm{PPh}_{3}\right)_{2}-\mathrm{H}_{2} \mathrm{C}_{2} \mathrm{O}$ (II). All calculations were performed using the GAUSSIAN 09 program package [13]. The geometry optimization of all the considered species was carried out by means of the DFT (B3LYP) method [14] using the LANL2DZ basis set with non-relativistic effective core potential for Pt [15] and the split-valence basis sets $6-31 G(d, p)[16]$ for all other atoms in the systems.

To estimate the values of the orbital charge transfers to and from coordinated ketene molecule, the calculated MOs of the complexes were rewritten in the basis of the eigenfunctions of the free ketene molecule and the atomic orbitals (AO) of other atoms. Then the changes in the occupations of MOs of coordinated molecule in the complexes are estimated from the difference in Mulliken populations of the corresponding orbitals.

\section{Results and discussion}

A general view of considered compounds, together with the relevant geometry parameters is shown in Figure 1. It can be seen that the geometry of the $\mathrm{C}_{2} \mathrm{H}_{2} \mathrm{O}$ molecule in the complexes is significantly different from that of the free molecule. In the ground ${ }^{1} \mathrm{~A}_{1}$ electronic state it is planar with the nuclear configuration of $\mathrm{C}_{2 \mathrm{v}}$ symmetry. In the complex $\mathrm{VCp}_{2}-\mathrm{H}_{2} \mathrm{C}_{2} \mathrm{O}$ the $\eta^{2}-(\mathrm{C}-\mathrm{O})$ binding mode takes place, the ketene molecule undergoes the in-plane distortion $\left(\angle \mathrm{C}-\mathrm{C}-\mathrm{O}=137.10^{\circ}\right)$ with the significant elongation of the $\mathrm{C}-\mathrm{O}$ bond $(1.29 \AA$ versus $1.17 \AA$ in free molecule). The same $\mathrm{C}-\mathrm{O}$ bond elongation and $\mathrm{C}-\mathrm{C}-\mathrm{O}$ moiety bending in $\eta^{2}-(\mathrm{C}-\mathrm{O})$ coordinated ketenes is also observed in other early transition metal complexes $[1,3,7]$. The $\eta^{2}-(\mathrm{C}-\mathrm{C})$ binding mode is preferred in the complex (II). The coordination is accompanied by the out-of-plane distortion of ketene molecule $\left(\angle \mathrm{C}-\mathrm{C}-\mathrm{O}=145.30^{\circ}\right.$ and 
$\left.\operatorname{dih}\left(\mathrm{C}-\mathrm{CH}_{2}\right)=22.7^{\circ}\right)$ and by significant elongation of the $\mathrm{C}-\mathrm{C}$ bond $(1.43 \AA$ versus $1.30 \AA$ in free molecule). The optimized geometry parameters agree well the experimental data for $\eta^{2}$-(C-C)-coordinated ketenes $[1,8]$.

It should be noted that the molecule also undergoes similar distortions in its excited states. It was established $[17,18]$ that in the lowest excited singlet ${ }^{1} \mathrm{~A}_{2}$ and triplet ${ }^{3} \mathrm{~A}_{2}$ electronic states ketene molecule undergoes the in-plane distortion leading to the planar $\mathrm{C}_{\mathrm{s}}$ structure, wherein the oxygen is bent away from the $\mathrm{C}$-C axis (Figure $1 d$ ). The second triplet excited ${ }^{3} \mathrm{~A}_{1}$ state is stabilized by the out-of-plane distortion to the pyramidal nuclear configuration also of $\mathrm{C}_{\mathrm{s}}$ symmetry, but the reflection plane in this case is perpendicular to the molecular plane of the $\mathrm{C}_{2 \mathrm{v}}$ structure (Figure $1 e$ ).

(a) ground ${ }^{1} \mathrm{~A}_{1}$ state

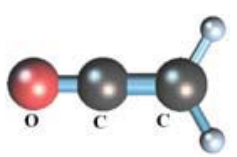

Planar $\mathbf{C}_{2 \mathrm{v}}$

(b)

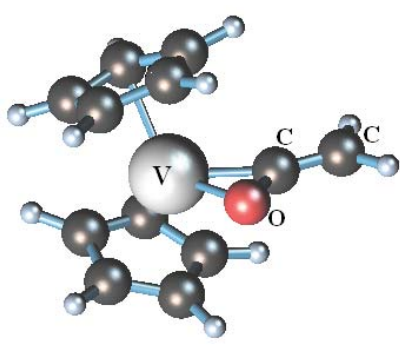

(c)

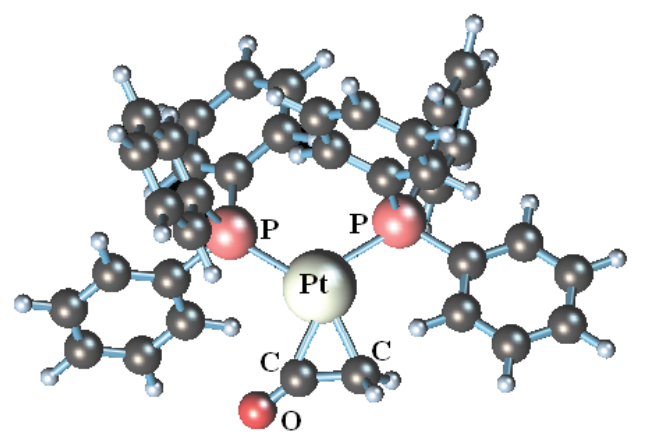

$R_{\mathrm{CC}}=1.30 \AA$
$R_{\mathrm{CO}}=1.17 \AA$ (d) excited ${ }^{3} \mathrm{~A}^{\prime}$ state

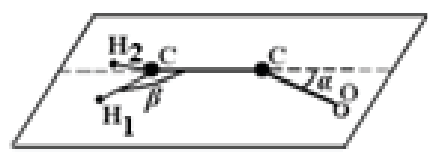

$$
\begin{aligned}
& R_{\mathrm{CC}}=1.34 \AA \\
& R_{\mathrm{CO}}=1.29 \AA \\
& \angle \mathrm{C}-\mathrm{C}-\mathrm{O}=137.1^{\circ} \\
& \operatorname{dih}\left(\mathrm{C}-\mathrm{CH}_{2}\right)=\mathbf{0}^{\circ}
\end{aligned}
$$

$$
\begin{aligned}
& R_{\mathrm{CC}}=1.45 \AA \\
& R_{\mathrm{CO}}=1.29 \AA \\
& \angle \mathrm{C}-\mathrm{C}-\mathrm{O}=\mathbf{1 2 0 . 4}^{\circ} \\
& \operatorname{dih}\left(\mathrm{C}-\mathrm{CH}{ }_{2}\right)=0^{\circ}
\end{aligned}
$$

(e) excited ${ }^{3} \mathrm{~A}^{\prime \prime}$ state

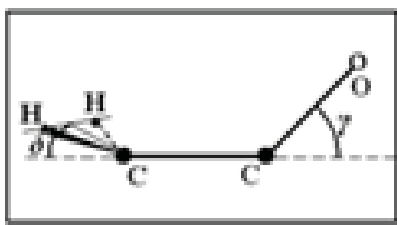

$$
\begin{aligned}
& R_{\mathrm{CC}}=1.43 \AA \\
& R_{\mathrm{CO}}=1.22 \AA \\
& \angle \mathrm{C}-\mathrm{C}-\mathrm{O}=145.3^{\circ} \\
& \operatorname{dih}\left(\mathrm{C}-\mathrm{CH}{ }_{2}\right)=22.7^{\circ}
\end{aligned}
$$

Figure 1. Optimized structures for (a) free ketene molecule in the ground ${ }^{1} \mathrm{~A}_{1}$ electronic state $\left(\mathrm{C}_{2 \mathrm{v}}\right)$, (b)- $\mathrm{VCp}_{2}-\mathrm{H}_{2} \mathrm{C}_{2} \mathrm{O}$ (I) complex, (c)- $\mathrm{Pt}\left(\mathrm{PPh}_{3}\right)_{2}-\mathrm{H}_{2} \mathrm{C}_{2} \mathrm{O}$ (II) complex,

(d)- ketene molecule in the first excited ${ }^{3} \mathrm{~A}^{\prime}$ state, $(e)$ ketene molecule in the second excited ${ }^{3} \mathrm{~A}^{\prime \prime}$ state.

Previously [19] we have shown that instability of the high-symmetry $\mathrm{C}_{2 \mathrm{v}}$ nuclear configuration of ketene molecule in the ${ }^{3} \mathrm{~A}_{2}$ and ${ }^{3} \mathrm{~A}_{1}$ excited states and the corresponding low-symmetry in-plane and out-of-plane distortions are due to the pseudo Jahn-Teller mixing of these states with higher excited ${ }^{3} \mathrm{~B}_{1}$ state. From this statement, some conclusions can be drawn, which may be useful in the analysis of distortions of coordinated ketene molecule. Given the fact that the ${ }^{3} \mathrm{~A}_{2}$ and ${ }^{3} \mathrm{~B}_{1}$ excited states, as well as the ${ }^{3} \mathrm{~A}_{1}$ and ${ }^{3} \mathrm{~B}_{1}$ states, differ from each other only by one spin-orbital, and the Hamiltonian $H$ is the sum of one-electron operators, the vibronic coupling constants and between these states are respectively equal to the orbital vibronic constants $f_{b 2}^{3 b 2,8 a 1}$ and $f_{b 1}^{3 b 1,8 a 1}$ (Eqs.(8)) mixing the vacant molecular orbitals $3 b_{2}$ and $8 a_{1}$, and $3 b_{1}$ and $8 a_{1}$ MOs, respectively. The $\mathrm{MO}$ level scheme of free $\mathrm{H}_{2} \mathrm{C}_{2} \mathrm{O}$ molecule is shown in Figure 2 on the left.

$$
\begin{aligned}
& F_{b 2}^{A_{2}, B_{1}}=f_{b 2}^{3 b 2,8 a 1}=\left\langle 3 b_{2}\left|\left(\partial H / \partial Q_{b 2}\right)_{0}\right| 8 a_{1}\right\rangle \\
& F_{b 1}^{A_{1}, B_{1}}=f_{b 1}^{3 b 1,8 a 1}=\left\langle 3 b_{1}\left|\left(\partial H / \partial Q_{b 1}\right)_{0}\right| 8 a_{1}\right\rangle
\end{aligned}
$$


From Eqs.(8) it is seen that the PJT contribution to the instability of the $\mathrm{C}_{2 \mathrm{v}}$ configuration of ketene molecule in considered ${ }^{3} \mathrm{~A}_{2}\left(2 b_{1} \rightarrow 3 b_{2}\right)$ and ${ }^{3} \mathrm{~A}_{1}\left(2 b_{1} \rightarrow 3 b_{1}\right)$ excited state is determined only by one OVCC, $f_{b 2}^{3 b 2,8 a 1}$ in the first case and $f_{b 1}^{3 b 1,8 a 1}$ in the second one. Therefore, we can assume that the corresponding anionic ${ }^{2} \mathrm{~B}_{2}\left(\ldots 2 b_{2}{ }^{2} 2 b_{1}{ }^{2} 3 b_{2}\right)$ and ${ }^{2} \mathrm{~B}_{1}\left(\ldots 2 b_{2}{ }^{2} 2 b_{1}{ }^{2} 3 b_{1}\right)$ states of ketene molecule are also unstable in the $\mathrm{C}_{2 \mathrm{v}}$ nuclear configuration with respect to considered $b_{2}$-type and $b_{1}$-type distortions due to the vibronic coupling of these states with the higher $\left.{ }^{2} \mathrm{~A}_{1(. .2} b_{2}{ }^{2} 2 b_{1}{ }^{2} 8 a_{1}\right)$ anionic state, with the same OVCCs as in Eqs.(8). Indeed, this is confirmed by calculations of the AP curves for the ${ }^{2} \mathrm{~B}_{2}$ and ${ }^{2} \mathrm{~B}_{1}$ anionic states along the $Q_{b 2}$ and $Q_{b 1}$ coordinates, respectively.

Based on the above, we can draw some conclusions about the binding modes and the distortions of coordinated ketene. If the back donation occurs on the LUMO $3 b_{2}$ (which is the antibonding with respect to the C-O bond), and if this charge transfer is large enough to satisfy the inequality (7), then the $\eta^{2}-(\mathrm{C}-\mathrm{O})$ coordination mode takes place, and the molecule undergoes the in-plane distortion of the $b_{2}$-type. The out-of-plane distortion of coordinated ketene can be realized only if the virtual $3 b_{1}$ MO acquires some additional charge by coordination. In free ketene molecule, this $3 b_{1}$ MO is much higher in energy (by $1.93 \mathrm{eV}$ ) than the LUMO $3 b_{2}$. However, calculations of the ketene cation show that $3 b_{1} \mathrm{MO}$ is significantly stabilized by ionization (difference in energies of $3 b_{1}$ and $3 b_{2}$ MOs is reduced to $0.13 \mathrm{eV}$ ). In the context of the problem under discussion, this means that the $\eta^{2}-(\mathrm{C}-\mathrm{C})$ coordination mode, as well as the out-ofplane distortion of the molecule can occur only as the result of a diorbital metal-ketene interaction. If the metal is able to form a bond with the occupied $2 b_{1} \mathrm{MO}\left(\pi_{\mathrm{C}-\mathrm{C}}\right)$, then the $\mathrm{C}-\mathrm{C}$ coordination mode is fixed, some electron density from the HOMO $2 b_{1}$ is transferred to the complex, thereby stabilizing the unoccupied $3 b_{1} \mathrm{MO}$, so the back donation to it becomes possible.

To reveal which orbital charge transfers to or from coordinated ketene molecule leading to its distortions take place in considered compounds, consider molecular orbitals of the complexes which are mainly involved in the vanadium-ketene and platinum-ketene binding (Figure 2). In the first case the $\mathrm{V}-\mathrm{H}_{2} \mathrm{C}_{2} \mathrm{O}$ binding is provided by forming of only one bonding MO which is composed from the filled $3 \mathrm{~d}_{\mathrm{xy}}$ orbital of vanadium and the LUMO $3 b_{2}$ of $\mathrm{C}_{2} \mathrm{H}_{2} \mathrm{O}$ (Figure 2), the orbital charge transfer is quite significant, $\Delta q\left(3 b_{2}\right)=0.46 \overline{\mathrm{e}}$. Due to forming of this MO the electron density transfers from the $3 d_{\mathrm{xy}}-\mathrm{AO}$ of the atom of $\mathrm{V}$ to the vacant $3 b_{2}$ - $\mathrm{MO}$ of the ketene molecule. Therefore, one can conclude that V-ketene bonding in the complex (I) is provided by the $\pi$-back donation from the transition metal to the ligand.

Then, the value of the curvature of the AP of coordinated ketene molecule with respect to the in-plane distortion of $b_{2}$-type can be estimated by Eq.(9):

$$
K_{b 2}^{\text {coord }}=K_{b 2}^{\text {free }}-2 \Delta q_{3 b 2}\left|f_{b 2}^{(3 b 2,8 a 1)}\right|^{2} / \Delta_{3 b 2,8 a 1}
$$

Substituting the calculated values of all the parameters: $K^{\text {free }}\left(b_{2}\right)=3.06 \mathrm{eV} / \AA^{2}, f_{b 2}{ }^{(3 b 2,8 a 1)}=6.16 \mathrm{eV} / \AA[19]$, and $\Delta=5.53 \mathrm{eV}$, we obtain $K^{\text {coord }}\left(b_{2}\right)=-3.25 \mathrm{~V} / \AA^{2}$.

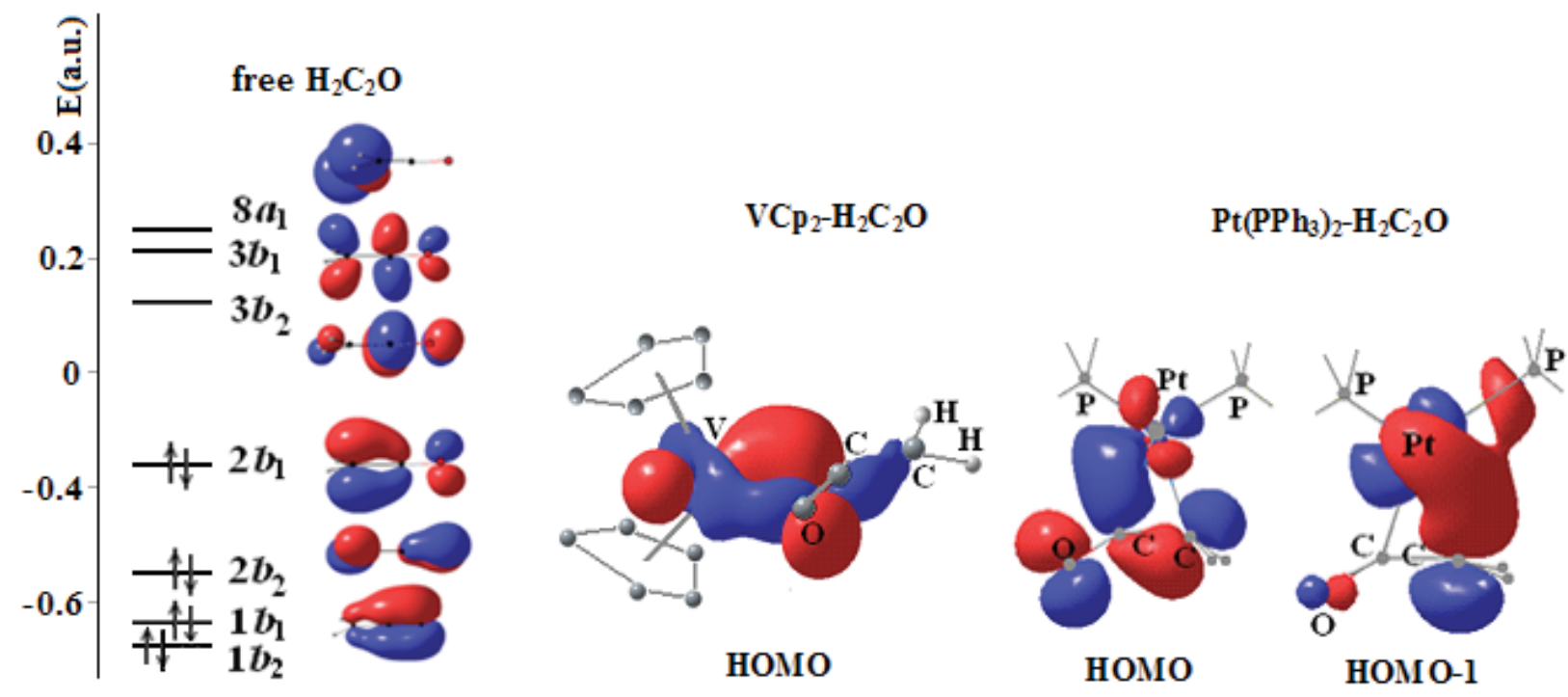

Figure 2. MO level scheme of free $\mathrm{H}_{2} \mathrm{C}_{2} \mathrm{O}$ molecule (left) and metal-ketene bonding molecular orbitals in $V \mathrm{Cp}_{2}-\mathrm{H}_{2} \mathrm{C}_{2} \mathrm{O}$ and $\mathrm{Pt}\left(\mathrm{PPh}_{3}\right)_{2}-\mathrm{H}_{2} \mathrm{C}_{2} \mathrm{O}$ complexes. 
In the $\mathrm{Pt}\left(\mathrm{PPh}_{3}\right)_{2}-\mathrm{H}_{2} \mathrm{C}_{2} \mathrm{O}$ complex the two bonding molecular orbitals are formed between the metal and ketene molecule (Figure 2). The HOMO of the complex is the linear combination of $5 d_{\mathrm{xy}} \mathrm{AO}$ of Pt and HOMO $2 b_{1}$ of ketene. Due to formation of this MO, some electronic density is transferred from the HOMO $2 b_{1}$ of ketene to the complex, thereby stabilizing the vacant $3 b_{1}$ orbital, as noted above. Analysis of the second bonding MO (HOMO-1) show that the same $5 d_{x y}-\mathrm{AO}$ of Pt interacts with the linear combination $\left(\left|2 b_{1}\right\rangle-\left|3 b_{1}\right\rangle\right)$ of ketene MOs, wherein the predominant contribution comes from the vacant $3 b_{1}$ MO. This HOMO-1 of the complex provides the OCT to the unoccupied ketene MO $3 b_{1}, \Delta q\left(3 \mathrm{~b}_{1}\right)=0.28 \mathrm{e}$. Thus, in this case, the corresponding metal orbitals can be considered as an interface in the electron density transfer from the HOMO $2 b_{1}$ of ketene molecule to its excited $3 b_{1}$ orbital. Then, the value of the $K^{\text {coord }}\left(b_{1}\right)$ with respect to the out-of-plane distortion of $b_{1}$-type can be estimated by Eq.(10).

$$
K_{b 1}^{\text {coord }}=K_{b 1}^{\text {free }}-2 \Delta q_{3 b 1}\left|f_{b 1}^{(3 b 1,8 a 1)}\right|^{2} / \Delta_{3 b 1,8 a 1}
$$

Calculated value of $K^{\text {free }}\left(b_{1}\right)$ is equal to $1.70 \mathrm{eV} / \AA^{2}, f_{\mathrm{b} 2}^{(3 \mathrm{~b} 1,8 \mathrm{a} 1)}=5.47 \mathrm{eV} / \AA[19], \Delta=3.56 \mathrm{eV}$, so that we obtain $K^{\text {coord }}\left(b_{1}\right)=-3.02 \mathrm{~V} / \AA^{2}$.

It is seen that in the coordinated state the curvature of the APES of the $\mathrm{H}_{2} \mathrm{C}_{2} \mathrm{O}$ molecule with respect to the bending modes becomes negative in both complexes. This explains the origin of the geometry of coordination of this molecule and provides for numerical estimates of the strength of distortion.

In the same approximation, by applying the JTE ideology to the ketene molecule with respect to the totally symmetric displacements of $\mathrm{A}_{1}$ type, we can explain also the significant elongation of its $\mathrm{C}-\mathrm{O}$ bond in the complex of vanadium, and elongation of $\mathrm{C}-\mathrm{C}$ bond by coordination to the complex of platinum. The diagonal vibronic coupling constant has the physical meaning of the force with which the electrons affect the nuclei in the direction of $Q$; in the $\mathrm{MO}$ approximation [12]. In the ground state equilibrium configuration of free $\mathrm{CH}_{2} \mathrm{CO}$ molecule the distorting force $F_{\mathrm{Al}}$ equals zero. After the charge transfers $\Delta q_{i}$ this force changes by $\Delta F(\mathbf{I})=\Delta q\left(3 b_{2}\right) f^{2 b 2,3 b 2}$, and $\Delta F(\mathbf{I I})=\Delta q\left(2 b_{1}\right) f^{2 b 1,2 b 1}+$ $\Delta q\left(3 b_{1}\right) f^{3 b 1,3 b 1}$. It was shown in [12] that for bonding MO $f^{(i)}>0$, and for antibonding MO $f^{(i)}<0$. Hence $f^{3 b 2,3 b 2}<0$ for the $\mathrm{C}-\mathrm{O}$ bond, $f^{2 b 1,2 b 1}>0$, and $f^{3 b 1,3 b 1}<0$ for the $\mathrm{C}-\mathrm{C}$ bond. Given that $\Delta q\left(2 b_{1}\right)<0, \Delta q\left(3 b_{1}\right)>0$, and $\Delta q\left(3 b_{2}\right)>0$, we get $\Delta F(\mathbf{I})<0$ for the $\mathrm{C}-\mathrm{O}$ bond in (I) and $\Delta F(\mathbf{I I})<0$ for the $\mathrm{C}-\mathrm{C}$ bond in (II). Thus, in the both cases the OCTs induce a JTE distorting force which pushes away the carbon and oxygen nuclei in (I), and the carbon nuclei in (II), thereby increasing the C-O and $\mathrm{C}-\mathrm{C}$ and bond lengths, respectively.

\section{Conclusions}

In this study, we have demonstrated that structural distortions of ketene molecule caused by their coordination to transition metal complexes may be interpreted as the consequences of the PJTE induced by the orbital charge transfers It is shown that the curvature of the AP of coordinated ketene respectively in the $b_{2}$ (in I) and $b_{1}$ (in II) directions becomes negative in both complexes, that explains the origin of the geometry of coordination of the molecule. The $\eta^{2}-(\mathrm{C}-\mathrm{O})$ coordination and the in-plane distortion of ketene in the complex of vanadium is due to the PJTE induced by the back donation to its LUMO $3 b_{2}\left(\pi_{\mathrm{CO}}{ }^{*}\right)$. The $\eta^{2}-(\mathrm{C}-\mathrm{C})$ coordination mode, as well as the out-of-plane distortion of the molecule in the complex of platinum is caused by the two charge transfers: from the HOMO $2 b_{1}\left(\pi_{\mathrm{CC}}\right)$ to the metal $d_{\mathrm{xy}}-\mathrm{AO}$, and from the same $\mathrm{AO}$ of Pt to the vacant $3 b_{1}\left(\pi_{\mathrm{CC}}{ }^{*}\right) \mathrm{MO}$ of ketene, thus being the result of diorbital Pt-ketene interaction.

The elongation of $\mathrm{C}-\mathrm{O}$ and $\mathrm{C}-\mathrm{C}$ bonds respectively in the complexes of vanadium and platinum as compared with the free ketene molecule is due to the change of the corresponding diagonal vibronic coupling constants which is induced by the orbital charge transfers by coordination.

\section{References}

1. Grotjahn, D.B.; Collins, L.S. B.; Wolpert, M.; Bikzhanova, G.A.; Lo, H.C.; Combs, D.; and Hubbard, J.L. First direct structural comparison of complexes of the same metal fragment to ketenes in both C,C- and C,O-bonding modes. Journal of American Chemical Society, 2001, 123, pp. 8260-8270.

2. Miyashita, A.; Shitara, H.; Nohira, H. Preparation and properties of platinum ketene complexes. Facile carboncarbon bond cleavage of coordinated ketene. Organometallics, 1985, 4, pp.1463-1464.

3. Antiñolo, A.; Otero, A.; Fajardo, M.; Lopez-Mardomingo, C.; Lucas, D.; Mugnier, Y.; Lanfranchi, M.; Pellinghelli, M.A. Early-transition-metal ketene complexes: Synthesis, reactivity and structure of ketene complexes of bis(trimethylsilyl)niobocene, X-ray structure of $\left[\mathrm{Nb}\left(\eta^{5}-\mathrm{C}_{5} \mathrm{H}_{4} \mathrm{SiMe}_{3}\right)_{2} \mathrm{Br}_{2}\left(\mathrm{Ph}_{2} \mathrm{C}=\mathrm{C}=\mathrm{O}, \eta^{2}-\mathrm{C}, \mathrm{O}\right)\right.$. Journal of Organometallic Chemistry, 1992, 435, pp. 55-72.

4. Miyashita, A.; Sugai, R.J.; Yamamoto, J.I. Synthesis and reactivities of novel $\eta^{2}-(\mathrm{C}, \mathrm{O})$ alkylphenylketene complexes of nickel. Coordination-mode switching reaction of the ketene ligand. Journal of Organometallic Chemistry, 1992, 428, pp. 239-247.

5. Wright, C.A.; Thorn, M.; McGill, J.W.; Sutterer, A.; Hinze, S.M.; Prince R.B.; and Gong, J.K. A first example of a 
"Wittig Reaction" on a coordinated carbon dioxide nickel complex. Journal of American Chemical Society, 1996, 118, pp. 10305-10306.

6. Waymouth, R.M.; Santarsiero, B.D.; Grubbs, R.H. Trigonal-bipyramidal methyl group bridging two zirconoceneketene centers. Journal of American Chemical Society, 1984, 106, pp. 4050-4051.

7. Hofmann, P.; Perez-Moya, L.A.; Stelgelmann, O.; Riede, J. $\eta^{2}-(\mathrm{C}, \mathrm{O})$ ketene coordination at nickel(0). Synthesis, bonding, and molecular structure of (dtbpm) Ni[ $\left.\eta^{2}-(\mathrm{C}, \mathrm{O})-\mathrm{Ph}_{2} \mathrm{C}_{2} \mathrm{O}\right]$ [dtbpm = bis(di-tert-butylphosphino)methane]. Organometallics, 1992, 11, pp. 1167-1176.

8. Liu, X.; Gong, J.K.; Seyler, J.W. Theoretical investigation of ketene bonding modes in bis(phosphine) palladium ketene complexes. Journal of Coordination Chemistry, 2000, 52, pp. 47-56.

9. Gorinchoy N.N.; Balan I.I.; Bersuker I.B. Jahn-Teller, pseudo Jahn-Teller, and Renner-Teller effects in systems with fractional charges. Computational and Theoretical Chemistry, 2011, 976, pp. 113-119.

10. Gorinchoy N. Jahn-Teller and pseudo Jahn-Teller origin of structural distortions of coordinated molecules. Revue Roumaine de Chimie, 2014, 59(3-4), pp. 273-280.

11. Gorinchoy N. Bending of adsorbed FCN and FNC molecules induced be the Renner-Teller effect. Annals of the West University of Timisoara, Physics series, 2012, 56, pp. 15-23.

12. Bersuker I.B. The Jahn-Teller Effect, Cambridge University Press, Cambridge (UK), 2006, 616 p.

13. Frisch, M.J.; Trucks, G.W.; Schlegel, H.B.; Scuseria, G.E.; Robb, M.A. et al. Gaussian 09, Revision B.01; Gaussian, Inc.: Wallingford, CT, 2009.

14. Lee, C.; Yang, W.; Parr, R.G. Development of the Colle-Salvetti correlation-energy formula into a functional of the electron density. Physical Review B, 1988, 37, pp. 785-789.

15. Hay, P.J.; Wadt, W.R. Ab initio effective core potentials for molecular calculations. Potentials for K to Au including the outermost core orbitals. Journal of Chemical Physics, 1985, 82, pp. 299-310.

16. Hehre, W.J.; Ditchfield, R.; Pople, J.A. Self-Consistent Molecular Orbital Methods. XII. Further extensions of Gaussian-type basis sets for use in molecular orbital studies of organic molecules. Journal of Chemical Physics, 1972, 56 pp. 2257-2261.

17. Dykstra, C.E.; Schaefer III, H.F. Excited electronic states of ketene. Journal of American Chemical Society, 1976, 98, pp. 2689-2695.

18. Szalay, P.G;. Császár, A.G.; Namas, L. Electronic states of ketene. Journal of Chemical Physics, 1996, 105, pp. 1034-1045.

19. Gorinchoy N. Electronic control of molecular configuration instability via vibronic coupling. Pseudo Jahn-Teller stabilization of vertically excited states of $\mathrm{F}_{2} \mathrm{CO}, \mathrm{N}_{2} \mathrm{H}_{2}$ and $\mathrm{H}_{2} \mathrm{C}_{2} \mathrm{O}$ molecules. Chemistry Journal of Moldova, 2014, 9(2), pp. 80-89. 